Original Article

\title{
APPLICATION OF STOOL ANTIGEN TEST FOR MONITORING HELICOBACTER PYLORI AMONG HUMAN IN ERBIL GOVERNORATE, KURDISTAN REGION/IRAQ
}

\author{
DHARY ALEWY ALMASHHADANY \\ Dhary Alewy Al-Mashhadany, Knowledge University, College of Science, Department of Pathological Analysis, Kurdistan Region, Erbil, \\ Iraq \\ Email: alewi1987@gmail.com \\ Received: 01 Aug 2018 Revised and Accepted: 26 Sep 2018
}

\begin{abstract}
Objective: This work was connected to screen Helicobacter pylori among human in Erbil Governorate by using stool antigen test (SAT).

Methods: In a clean and sterile container, three hundred stool samples were collected from both sexes during the period from July-December 2017. Samples were collected from 150 males at the rural and an urban area in equal number, similarly 150 females same areas. The collected samples were tested in Microbiology Laboratory, Department of Pathological Analysis using One-Step H. pylori Antigen Test Kit.

Results: The obtained results shown that the prevalence of $H$. pylori in total samples were $(11.3 \%)$. The rate of infection among females were $(12.7 \%)$ compared to $(10.0 \%)$ of male infection rate. According to the age wise of the patients $(11-20,51-60$ and above 60 y) results showed that the $H$. pylori antigen rates were $(16.3 \%, 11.9 \%$, and $13.6 \%)$ respectively that mean the high rate of infection was varied. According to habitation, the high rate of $H$. pylori among males was $12.0 \%$ and $8.0 \%$ in rural and urban area consecutively. While the occurrence rate of $H$. pylori antigen among female was high $14.7 \%$ in rural area, compared to $10.7 \%$ in the female of the urban area. The proportion of $H$. pylori antigen rate in September, December and October were $(16.0 \%, 14.0 \%$, and $12.0 \%)$ respectively.
\end{abstract}

Conclusion: From this study, we concluded that the prevalence of H. pylori among human in Erbil Governorate was high, and the infection takes place in the early years of life. The significance of public health risks was discussed.

Keywords: Application, Stool Antigen Test, H. pylori, Human, Erbil Governorate, urdistan region, Iraq

(C) 2018 The Authors. Published by Innovare Academic Sciences Pvt Ltd. This is an open-access article under the CC BY license (http://creativecommons.org/licenses/by/4.0/) DOI: http://dx.doi.org/10.22159/ijpps.2018v10i11.28872

\section{INTRODUCTION}

Helicobacter pylori is associated with gastro-duodenal infections in human. H. pylori have been found strongly related to chronic gastritis, duodenal ulcer, gastric carcinoma, and mucosa-associated lymphoid malignancies. Gastric cancer is the most common infection-related cancer globally, which led to the categorization of H.pylori as a class one human carcinogen by the international agency for research on cancer (IARC), also several researchers confirmed that $H$. pylori is the most common infectious human pathogen [1-3].

Basically, H. pylori have a narrow host range and found in humans and some nonhuman primates. Occasionally, H. pylori have been isolated from domestic animals, but until now there is no available evidence for zoonotic transmission of $H$. pylori. Several investigations address the role of food in the transmission of $H$. pylori. Food is a reasonable source of infections with $H$. pylori, and there are several investigations which address the role of food in the transmission of $H$. pylori. Various works support the suggestion of $\mathrm{H}$. pylori waterborne pollution, and there are abundant epidemiological works have indicated positive relations between untreated or fecal polluted drinking water and occurrence of $H$. pylori contamination. Also, several studies have reported the presence of H. pylori DNA in the environmental water sources [4-7].

H. pylori are actually a frequent infection all over the world. It is one of the world's most common public health issues. The rate of $H$ pylori infection is still high in most of the countries. There were approximately 4.4 billion individuals among both developed, and developing countries are infected with H. pylori worldwide in 2015 making it one of the most debatable bacteria in the world. Over $80 \%$ of individuals infected with the bacterium are asymptomatic. In diverse developing countries, more than $80 \%$ of the people are $H$. pylori positive, while in developed countries in general remains below $40 \%$ and is significantly lower in children and adolescents than in adults and elderly people [8-9].
In daily medical career, the use of a single test is usually sufficient, and most tests are adequately perfect to be used for this purpose, also the use of serology is most suitable for large epidemiological studies. The application of Stool Antigen Test (SAT) for general detection of $H$. pylori offers the opportunity to evaluate $H$. pylori condition without the need for endoscopy or venal puncture [10-11].

The objectives of this investigation were to monitor the prevalence of $H$. pylori among human males and females in both Rural and Urban areas.

\section{MATERIALS AND METHODS}

\section{Study design and sampling}

Three hundred (300) human stool samples were collected during the period from July 2017 to December 2017. Samples were collected from 150 male (comprised75 samples from rural area and75 samples from an urban area), and 150 female (included 75 samples from the rural area and 75 samples from an urban area). All males and females ranged in age from one year to more than $>61 \mathrm{y}$. Stool specimens were collected in sterile containers [12]. The collected samples were forwarded to the Microbiology Laboratory, Department of Pathological Analysis/College of Science/Knowledge University.

\section{Personal information}

Information about persons was recorded, including gender, age, and place of habitation. This work has been connected according to the Order No: PL/KU11/2017. From the Department of Pathological Analysis, College of Science/Knowledge University. Dated on 15/May/2017, to Dr. Dhary Alewy Almashhadany to screen the rate of pathogenesis rate of $H$. pylori in rural and an urban area in Erbil.

\section{Detection of $\boldsymbol{H}$. pylori antigen in stool}

In the laboratory, the detection of H. pylori antigen in stool samples was done by using the One-Step H. pylori Antigen Test Card (RAPID 
TEST/www. plasmatec. uk. com) fig. 1. The test was carried out according to [13]. The subsequent steps were followed:

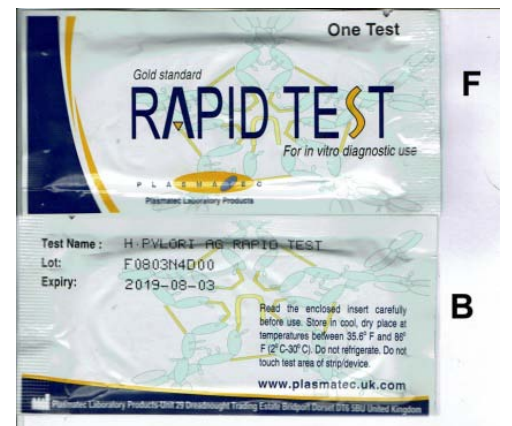

Fig 1

Fig. 1: Photo of the kit $(\mathrm{F}=$ front, $\mathrm{B}=$ back $)$

\section{Samples preparation}

All materials and specimens were put in room temperature before used. The sample bottles unscrewed. With the help of an attached applicator stick on the cap a small piece of stool (5-6 mm in diameter, approximately $100 \mathrm{mg}-200 \mathrm{mg} / 0.1-0.2 \mathrm{~g}$ ) transferred into the sample bottle containing specimen preparation buffer. The sticks in the bottles were replaced again to the specific bottles according to the giving numbers and tighten securely. Stool sample with the buffer mixed thoroughly by shaking the bottle for a few seconds.

\section{Testing of the samples}

Test cards were removed from the sealed foil pouch and the sample bottles well shake before the test performed. The bottles were held properly in a vertical position over the sample, about 3 drops (120$150 \mu \mathrm{l}$ ) of diluted stool sample to the sample hole. The result was read within 10-15 min. A strong positive sample may show the result earlier.

\section{Interpretation of result \\ Positive result}

A distinct pink coloured band appears on test line regions, in addition to a pink line in the control line region.

\section{Negative result}

No line appears in the test line region. A distinct pink line shows in the control line region.

\section{Statistical analysis}

Data were analyzed using the Chi-Square test and SPSS software version 15

\section{RESULTS}

\section{Prevalence of $\boldsymbol{H}$. pylori among human according to gender}

Table 1 shown that the total prevalence of $H$. pylori among human was $34(11.3 \%)$, also the result showed that the females is more exposed $19(12.7 \%)$ to the infection with H. pylori, compared with male rate $15(10.0 \%)$.

Table 1: Prevalence of $\boldsymbol{H}$. pylori according to gender

\begin{tabular}{|c|c|c|c|c|c|c|c|}
\hline \multirow[t]{2}{*}{ Gender } & \multirow[t]{2}{*}{ No of samples examined } & \multicolumn{2}{|c|}{ Positive } & \multicolumn{2}{|c|}{ Negative } & \multirow[t]{2}{*}{ Chi-square } & \multirow[t]{2}{*}{ P value } \\
\hline & & No & $\%$ & No & $\%$ & & \\
\hline Male & 150 & 15 & 10.0 & 135 & 90.0 & 0.531 & $0.466 \mathrm{NS}$ \\
\hline Female & 150 & 19 & 12.7 & 131 & 87.3 & & \\
\hline Total & 300 & 34 & 11.3 & 266 & 88.7 & & \\
\hline
\end{tabular}

\section{Prevalence of $\boldsymbol{H}$. pylori according to age}

The obtained result in table 2 showed that the occurrence rate of $H$. pylori was high (16.3\%) among the age group between 11-20 y, followed by the group which aged more than sixty-one $>61$ y $(13.6 \%)$, and the lower occurrence rate was observed in the group aged between 51-60 y (11.9\%).

Table 2: Prevalence of $\boldsymbol{H}$. pylori antigens according to age

\begin{tabular}{|c|c|c|c|c|c|c|c|}
\hline \multirow{2}{*}{$\begin{array}{l}\text { Age group } \\
\text { (Years) }\end{array}$} & \multirow[t]{2}{*}{ No of samples examined } & \multicolumn{2}{|c|}{ Positive } & \multicolumn{2}{|c|}{ Negative } & \multirow[t]{2}{*}{ Chi-square } & \multirow[t]{2}{*}{$P$ value } \\
\hline & & No & $\%$ & No & $\%$ & & \\
\hline $1-10$ & 42 & 3 & 7.1 & 39 & 92.9 & 2.307 & $0.889 \mathrm{NS}$ \\
\hline $11-20$ & 43 & 7 & 16.3 & 36 & 83.7 & & \\
\hline $21-30$ & 45 & 5 & 11.1 & 40 & 88.9 & & \\
\hline $31-40$ & 43 & 4 & 9.3 & 39 & 90.7 & & \\
\hline $41-50$ & 41 & 4 & 9.8 & 37 & 90.2 & & \\
\hline $51-60$ & 42 & 5 & 11.9 & 37 & 88.1 & & \\
\hline$>61$ & 44 & 6 & 13.6 & 38 & 86.4 & & \\
\hline Total & 300 & 34 & 11.3 & 266 & 88.7 & & \\
\hline
\end{tabular}

\section{Prevalence of $\boldsymbol{H}$. pylori in males according to habitation site}

According to table 3 the habitation site of the male participants shown that the high proportion of $H$. pylori antigen was $(12.0 \%)$ in a rural area, whereas $(8.0 \%)$ among an urban area.

\section{Prevalence of $\boldsymbol{H}$. pylori in females according to habitation site}

In table 4 results indicate that the incidence rate of $H$. pylori was high $(14.7 \%)$ in female participants among rural area, whereas $(10.7 \%)$ in female participants among an urban area.

Table 3: Prevalence of $H$. pylori in male's samples

\begin{tabular}{lllllll}
\hline Habitation site & No of samples examined & \multicolumn{2}{l}{ Positive } & \multicolumn{2}{l}{ Negative } & \multicolumn{2}{c}{ Chi square } \\
\cline { 3 - 5 } & & No. & $\%$ & No. & $\%$ & 0.667 \\
\hline Rural Area & 75 & 9 & 12.0 & 66 & 88.0 & 92 \\
Urban Area & 75 & 6 & 8.0 & 69 & 0.414 \\
Total & 150 & 15 & 10.0 & 135 & 90.0 & NS \\
\hline
\end{tabular}


Table 4: Prevalence of $H$. pylori in female's samples

\begin{tabular}{lllllll}
\hline Habitation site & No of samples examined & \multicolumn{2}{l}{ Positive } & \multicolumn{2}{l}{ Negative } & \multicolumn{2}{c}{ Chi square } \\
\cline { 3 - 5 } & & No. & \% & No. & \% & \\
\hline Rural Area & 75 & 11 & 14.7 & 64 & 85.3 & 0.542 \\
Urban Area & 75 & 8 & 10.7 & 67 & 89.3 & 0.461 \\
Total & 150 & 19 & 12.7 & 131 & 87.3 & NS \\
\hline
\end{tabular}

The relationship between months and prevalence of $\boldsymbol{H}$. pylori during the period of study

Table 5 points up the relationship between months and prevalence of $H$. pylori among human during the period of study. From this table we indicated that the highest rate of occurrence of $H$. pylori was founded in September (16.0\%), then in December (14.0\%), while the lowest rate was found in July and August (8.0\%) for both of them.

Table 5: Relationship between Months and prevalence of $\boldsymbol{H}$. pylori

\begin{tabular}{lllll}
\hline Month & No of samples examined & H. pylori antigen & Chi-square & P Value \\
\cline { 3 - 4 } & & No & \% & 2.654 \\
\hline July & 50 & 4 & 8.0 & 0.753 \\
August & 50 & 4 & 8.0 & NS \\
September & 50 & 8 & 16.0 & 12.0 \\
October & 50 & 6 & 10.0 & 14.0 \\
November & 50 & 5 & 11.3 & \\
December & 50 & 7 & 34 & \\
Total & 300 & & & \\
\hline
\end{tabular}

\section{DISCUSSION}

H. pylori is a very sophisticated bacteria which is prevalent all over the world. The accurate timing of acquirement of H. pylori is unknown. The epidemiological evidence illustrated that infection takes place mostly in children under the age of $5 \mathrm{y}$, that is mean most of the people acquire $H$. pylori infection during their early childhood [14].

Several studies reported that $90 \%$ of duodenal ulcers and $70 \%$ of gastric ulcers are related to $H$. pylori infections. It is the major cause of peptic ulcer disease and gastric cancer, further, it possesses the enzyme urease, which hydrolyzes urea in the stomach into carbon dioxide and ammonia. This enables the survival of the bacterium in the acidic environment of the stomach, and causes bad breath (halitosis) and belching for the person and it equalizes the acidifying effects of hydrochloric acid [2-3]

Noninvasive tests are of major significance for assessment of the patient's status concerning infection by H. pylori. Stool antigen test (SAT) is an affordable, simple, low cost, sensitive, easiest methods to apply, also is considered the rapid diagnostic technique which is reliable, and the most globally used for identifying $H$. pylori.

In the present study, the prevalence of $H$. pylori among human was $11.3 \%$. This value is an approach to those reported in Makkah city, Saudi Arabia (12.3\%) [15], slightly approach with Namakin and Nejad [16] in Iran, who found the prevalence of $H$. pylori colonization in 282 students was $13.1 \%$. However, our finding was lower than those reported in some other countries by using SAT, the prevalence of H. pylori infection in Turkey was $63 \%$ [17], 66.0\% in China [18], and $37.8 \%$ in Iran [19].

In other hand, Sykora [20] found the prevalence of $H$. pylori infection in asymptomatic children in the Czech Republic at a rate of $7 \%$. Recent studies conducted by several researchers reported different ranges of H. pylori infection; Daugule et al., [221] in Latvia confirmed that $(17.7 \%)$ of the total 220 patient samples was positive to SAT; in Korea Moon et al., [22] reported that from 318 seropositive subjects, 256 (80.5\%) showed positive stool test; El-shabrawi et al., [23] in Egypt, reported that the H. pylori SAT test was positive in $34(89.5 \%)$ out of the 38 patients.

Also from table 1, we noticed that the highest rate of prevalence of $H$. pylori antigens was found in female $(12.7 \%)$, while the lowest rate of prevalence was found in male $(10.0 \%)$, that means no significant differences between the prevalence rate among sexes at tha value of ( $p>0.05)$. This data was consistent with Yucel et al., [17] in Turkey, who stated that the exposed to infection with $H$. pylori in females
(76.2\%) compared with $(23.8 \%)$ in male by using monoclonal $H$. pylori SAT test. Elshiekh et al., [24] in Egypt, reported that the rate of infection in females and males were $52 \%$ and $48 \%$ consecutively. While in a different way the results in this work inconsistent with Faisal et al., [25] in Pakistan, who declared that the prevalence of $H$. pylori infection in female was $28.6 \%$, while in male was $71.4 \%$.

In table 2 the prevalence of $H$. pylori antigens among human in the age shown that there are no significant differences in the $H$. pylori antigen test between age groups according to positive and negative results in the value of $(\mathrm{p}>0.05)$.

The current result was incompatible with the result stated by Mayass [13], who confirmed that the prevalence of $H$. pylori antigen among human stool samples was $(18.4 \%)$, they found that the high prevalence rate of $H$. pylori antigen in the stool of children was between the age group of 11-15 y (28.6\%), followed by the children with age group between one month-5 y (9.7\%), whereas the prevalence of $H$. pylori antigen from adult stool was high in the ages between $46-55$ y (25.0\%), followed by group with age between 2635 y (23.4\%), then from 56-65 y were (23.1\%), after that from 36-45 y $(18.2 \%)$, finally the age of $16-25$ y were (15.4\%). Bader et al., [26] in Egypt found that the prevalence of $H$. pylori antigen in the stool of children $<5$ y was $30 \%$, followed by age group between $5-10$ y was ( $40 \%$ ), finally age group $>10$ y the rate was $(20 \%)$. In Yemen (Taiz city), Naji et al., [27] reported that the stool antigen was positive in (49\%) out of 100 samples tested, and the majority of cases were in the age group between 40-49 $\mathrm{y}$, also they confirmed that the predominance of infection was for the female.

Recently AL-Sinani et al., [28] in Oman, the general occurrence of $H$. pylori in Omani children increased from $7 \%$ in an age of less than five years to $33 \%$ in the age group between 5-10 y. Also, Awuku et al., [29] in Ghana, stated that the overall prevalence of $H$. pylori infection among children was $14.2 \%$, and the age group with the lowest $H$. pylori infection rate was 14-16 y with the prevalence of $11.9 \%$, they also noticed that a female: male ratio of $1.3: 1$, with a higher ratio of females $(16.8 \%)$ having $H$. pylori infection, compared to males $(10.7 \%)$.

The high incidence of $H$. pylori infection in adult life can possibly be elucidated by the exposure of the community to $H$. pylori early in life because of risk factors, like poor sanitation, lack of proper hygiene and increased receptivity due to a genetic tendency. Overcrowding is a risk factor for acquisition of $H$. pylori infection in children; contaminated water and food also act as sources of infection. The epidemiological articles published at the start of this decade. 
supported the indication that $H$. pylori are most common in impoverished areas with poor sanitation, overcrowding, low socioeconomic status, as well as the level of educational background, and rates of immigrant children from the adjacent cities are important risk factors for $H$. pylori infection among children. Transmission occurs during childhood through an oral-oral or a fecal-oral route [30-31].

According to the table 3, we observed that the high dominance of $H$. pylori antigen among males were $(12.0 \%)$ and $(8.0 \%)$ in rural and an urban area consecutively. That means $H$. pylori was prevalent in both of these areas. There is no significant difference in the $H$. pylori antigen test for male according to habitation for positive and negative samples $(\mathrm{p}>0.05)$

Similarly, table 4 shown that the incidence rate of $H$. pylori antigen was high (14.7\%) in female participants among rural area, whereas $(10.7 \%)$ in female participants among an urban area. The obtained results indicated that there was no significant difference at the level of $(\mathrm{p}>0.05)$ in the $H$. pylori antigen test for females, according to habitation site for positive and negative examined samples.

The relationship between months and prevalence of $H$. pylori antigen during a study period were recorded. Results in table 5 clarify that the prevalence increased in September (16.0\%), December (14.0\%), October $12.0 \%$, and November $10.0 \%$. While in the month of July and August, the prevalence rate was $(8.0 \%)$ for both. The statistical analysis of differences in the $H$. pylori antigen test for six months, according to our results shown that there were no significant differences in $(p>0.05)$. The results are compatible somewhat with the work conducted by Mayass [13], who indicated that the prevalence increased in March and September (100\%). After that in May and February, the incidence rate was (95.45\%) and (95.00\%) consecutively. Mayass [13] also reported that the rate of occurrence was declined whenever moved away from these months, in June $(79.17 \%)$, July $(75.00 \%)$, followed by October $(73.91 \%)$, August (70.83\%), lastly in April (56.52\%). There are some limitations of our present work. First, the persons shown discomfort regarding specimen sampling. The sensitivity of this test decreases after using of the proton pump inhibitor therapy (PPI), bismuth and antibiotic.

\section{CONCLUSION}

H. pylori is one of a significant public health challenge for Iraqi Kurdistan. According to the results obtained from this work, we concluded that the occurrence of $H$. pylori antigen among humans in Erbil Governorate was so high. The significant occurrence of H. pylori infection may be due to overcrowding, socioeconomic status, level of educational background, family dietary, sanitary conditions, and rates of immigrant children from the adjacent towns or maybe because of other risk factors, like bad sanitation, lack of proper hygiene, and increased susceptibility as a result of a genetic tendency.

\section{AUTHORS CONTRIBUTIONS}

All the author have contributed equally

\section{CONFLICT OF INTERESTS}

The author declared that he has no conflict of interest

\section{REFERENCES}

1. Abdel Latif ME, Shahin R, Abdrabou RM, Shawqy A, El-Ghadban $\mathrm{HM}$, Arafa $\mathrm{M}$, et al. Value of additional corpus biopsy for diagnosis of Helicobacter pylori in atrophic gastritis. J Gastrol Hepatol Dis 2016;2:108.

2. Rana R, Wang SL, Li J, Wang YX, Rao QW, Yang CQ. Helicobacter pylori infection: a recent approach to diagnosis and management. J Biomed 2017;2:45-56.

3. Gonzalez Pons M, Soto Salgado M, Sevilla J, Marquez-Lespier JM, Morgan D, Perez CM, et al. Seroprevalence of Helicobacter pylori in hispanics living in puerto rico: a population-based study. Helicobacte 2018;23:e12453.

4. Queralt N, Bartolome R, Araujo R. Detection of Helicobacter pylori DNA in human feces and water with different levels of fecal pollution in the north-east of spain. J Appl Microbiol 2005;98:889-95.
5. Vale FF, Vitor JMB. Transmission pathway of Helicobacter pylori: does food play a role in rural and urban areas? Int J Food Microl 2010;138:1-12.

6. Zamani M, Vahedi A, Maghdouri Z, Shokri-Shirvani J. Role of food in the environmental transmission of Helicobacter pylori. Caspian J Intern Med 2017;8:146-52.

7. Boehnke KF, Brewster RK, Sanchez BN, Valdivieso M, Bussalleu A, Guevara M, Saenz CG, et al. An assessment of drinking water contamination with Helicobacter pylori in Lima, Peru. Helicobacter 2018;32:e12462.

8. Chey WD, Leontiadis GI, Howden CW, Moss SF. Treatment of Helicobacter pylori infection. Am J Gastroenterol 2017;112:212-38.

9. Doulberis M, Kotronis G, Thomann R, Polyzos SA, Boziki M, Gialamprinou D, et al. Impact of Helicobacter pylori on Alzheimer disease: what do we know so far? review. Helicobacter 2018;23:e12454, 1-6.

10. Jemilohun AC, Otegbayo JA. Helicobacter pylori infection: past, present, and future. Pan African Med J 2016;23:216.

11. Bjorkman DJ. High worldwide variation in the prevalence of Helicobacter pylori infection. NEJM J Watch 2018;47:868.

12. Falsafi T, Valizadeh N, Najafi M, Ehsani A, Khani A, Landarani Z, et al. Culture of Helicobacter pylori from stool samples in children. Can J Microbiol 2007;53:411-6.

13. Mayass SMA. Prevalence of Helicobacter pylori in human and food and study the effect of garlic extract on isolated bacteria in thamar province. M. Sc. thesis in Microbiology, Department of Biology, Faculty of Applied Science, Thamar University, Thamar, Yemen; 2013.

14. Kienesberger S, Perez Perez GI, Olivares AZ, Bardhan P, Sarker SA, Hasan KZ, et al. When are Helicobacter pylori acquired in populations in developing countries? A birth-cohort study in Bangladeshi children. Gut Microbes 2018;1:1-12.

15. Ashgar SS. Helicobacter Pylori diagnosis by stool antigen ELISA and rapid test. J Appl Med Sci 2013;4:61-6.

16. Namakin K, Nejad FB. Prevalence of Helicobacter pylori infection in asymptomatic children in birjand, Eastern Iran. Inter J Ped 2014;2:55-63.

17. Yucel T, Aygin D, Sen S, Yucel O. The prevalence of Helicobacter pylori and related factors among University student in Turkey. Japan J Inf Dis 2008;61:179-83.

18. Zhang DH, zhouly LY, Lin SR, Ding SG, Huang YH, Guf F, et al. Recent changes in the prevalence of Helicobacter pylori infection among children and adults in high-or-low-incidence regions of gastric cancer in China. Chin Med J Eng 12009;122:1759-63.

19. Iranikhah A, Ghadir MR, Sarkeshikian S, Hosein Saneian H, Heiari A, Mahari M. Stool antigen tests for the detection of Helicobacter Pylori in children. Iran J Ped 2013;23:138-42.

20. Sýkora J, Siala K, Varvarovska J, Pazdiora P, Pomahacova R, Huml M. Epidemiology of Helicobacter pylori infection in asymptomatic children: a prospective population-based study from the Czech Republic. Application of a monoclonal-based antigen-in-stool enzyme immunoassay. Helicobacter 2009;4:286-97.

21. Daugule I, Karklina D, Remberga S, Rumba-Rozenfelde I Helicobacter pylori infection and risk factors in relation to allergy in children. Pediatr Gastroenterol Hepatol Nutr 2017;20:216-21.

22. Moon HW, Lee SY, Hur M, Yun YM. Characteristics of Helicobacter pylori-seropositive subjects according to the stool antigen test findings: a prospective study. Korean J Intern Med 2018;33: 893-901.

23. El-Shabrawi M, El-Aziz NA, El-Adly TZ, Hassanin F, Eskander A, Abou-Zekri M, et al. Stool antigen detection versus $13 \mathrm{C}$-urea breath test for non-invasive diagnosis of pediatric Helicobacter pylori infection in a limited resource setting. Arch Med Sci 2018;14:69-73.

24. Elshiekh HRM, Elrabat AM, Sultan AM, Zaky MM. Bacteriological investigation of Helicobacter pylori infections in patients with gastric and duodenal ulcer. Int J Curr Microbiol Appl Sci 2017;6:2753-65.

25. Faisal N, UL Haq MM, Mbbs HS, Ashraf P, Esmail JH. Helicobacter pylori infection; dyspeptic patients undergoing endoscopy; a hospital-based study. Professional Med J 2012;19:202-7. 
26. Badr MA, El-Saadany HF, Ali ASA, Abdelrahman D. Study of H. Pylori infection in children with recurrent abdominal pain attending the pediatrics outpatient clinic of zagazig university hospitals. J Egypt Soc Parasit 2012;42:735-40.

27. Naji AS, A-Ameri GA, Ekadasi MN, Hanash S, Wahid AM, Ali WAM, et al. Comparison of stool antigen and blood antibody test methods for detection of Helicobacter pylori infection and the risk factors. Int J Curr Microbiol Appl Sci 2014;3:118-27.

28. Al-Sinani S, Al-Mulaabed SW, Al-Naamani K, Al-Sharji H. Helicobacter Pylori infection in omani children. Helicobacter 2017;22:306-11.
29. Awuku YA, Simpson DL, Alhassan IK, Tuoyire DA, Afaa T, Adu P. Prevalence of Helicobacter pylori infection among children living in a rural setting in sub-saharan Africa. BMC Public Health 2017;17:1-6.

30. Sharma M, Mehta P, Vohra P. Incidence of Helicobacter Pylori in patients with gastroduodenal disorders. Inno J Med Health Sci 2013;3:10-5.

31. Miernyk KM, Bulkow LR, Gold BD, Bruce MG, Hurlburt DH, Griffin PM, et al. Prevalence of Helicobacter pylori among alaskans: factors associated with infection and comparison of urea breath test and anti-Helicobacter pylori IgG antibodies. Helicobacter 2018;23. e12482.1-8. 